\title{
The analysis of influence of polymer admixtures on properties of lightweight concrete
}

\author{
Jacek Góra ${ }^{1}$, Danuta Barnat-Hunek ${ }^{1}$, Paweł Wlaź ${ }^{2}$, and Monika Garbacz ${ }^{3, *}$ \\ ${ }^{1}$ Lublin University of Technology, Faculty of Civil Engineering and Architecture, Nadbystrzycka 40, 20-618 Lublin, Poland \\ ${ }^{2}$ Lublin University of Technology, Faculty of Fundamentals of Technology, Nadbystrzycka 38, 20-618 Lublin, Poland \\ ${ }^{3}$ Lublin University of Technology, Faculty of Environmental Engineering, Nadbystrzycka 40B, 20-618 Lublin, Poland
}

\begin{abstract}
The article presents the results of testing physical and strength properties of concrete with the addition of lightweight perlite in the amount of 10 and $20 \%$. The additive was introduced by volume substituting a part of the sand. In addition, the effect of using siloxane admixtures and a vinyl acetate copolymer with different degree of dosing, as well as applied simultaneously, were analysed. The tests were carried out in the field of bulk density and proper density, determination of tightness and porosity, compressive strength and tensile strength after 28 days of maturation. In terms of durability of concrete, absorption and resistance of concretes to the freeze-up effects after 100 freezing and thawing cycles were tested. The results of the study were subjected to statistical analysis using the analysis of variance. The analysed factors of influence were the amount of perlite addition, as well as the type and amount of the added admixture
\end{abstract}

\section{Introduction}

Nowadays, following the trend of energy-efficient construction, building lightweight concretes undergo modifications to achieve greater thermal insulation in order to reduce the heat emission from the building, and decrease the weight of the structure $[1,2]$. The lightweight aggregates are added to concrete in order to improve the thermal properties, reduce the effects of water condensation and minimise the transfer of heat through thermal bridges [3], the impact of which is significantly visible especially in the Eastern and Northern Europe [4]. In lightweight concrete, the amount of typical aggregate, such as sand, is being reduced and replaced by the lightweight aggregates [3-11]. Lightweight concrete uses recycled lightweight aggregate such as rubber granules [7], lightweight expanded clay aggregates [8], pumice, volcanic tuff and diatomite [9], sugarcane bagasse ash [10], recycled polypropylene plastic particles [11].

The studies on lightweight concrete with perlite are shown in the paper by Barnat-Hunek et al. [12]. It was found that replacing sand with lightweight aggregates decreased the density, compressive strength, and thermal conductivity of materials $[1-3,6,12]$. The mixtures containing the lightweight aggregate such as cork, had a higher coefficient of vapour permeability and smaller thermal conductivity coefficient than the reference samples [2]. On the other hand, Sidiqque R. [13] reports that when lightweight materials are used as concrete aggregates, they may not be very durable when subjected to freezing and thawing or abrasion. The resistance of lightweight concrete to the freezing-thawing phenomenon depends on the degree of saturation with water, layout of pores in hardened cement paste, and the type of aggregate used. Low permeability and low water/binder ratio constitute the basic properties characterising the concrete with high freezing-thawing resistance [12, 14]. Generally, the cracks in lightweight concrete appear for a number of reasons, including shrinkage in hardened concrete [15] or the frost attack [16]. These cracks weaken the waterproofing properties of concrete, as well as expose its microstructure to harmful factors and substances, including moisture, chlorides and other salts [12]. Cracks appear more frequently in lightweight concretes due to their lower strength and frost resistance than normal or high-performance concretes [17]. Polymer admixtures, for example, ethylene vinyl acetate copolymer are used to produce a more durable and waterproof structure of the concrete. When added in large amounts, admixtures may cause undesired changes in concrete properties, for example strength, absorptivity or water-tightness $[1,2$, 18].

The aim of the research presented in this paper was to evaluate the physical properties of lightweight concrete with perlite containing different polymer admixtures. In our opinion, the mixtures between perlite and cement/sand/admixture, particularly the change of their microstructure, are an important topic which needs to be developed and studied concerning the strength, wettability and durability of concrete. In order to clarify and confirm whether the additives and admixtures used have a significant impact on the tested concrete properties, the results of the study were subjected to a detailed statistical analysis. In addition, an SEM

* Corresponding author: monika.garbacz@interia.pl 
microscopic image analysis was used to assess the changes in the concrete microstructure.

\section{Materials and methods}

\subsection{Materials}

Composition of concrete mixtures is given in table 1 . In all concretes were maintained the same coefficient of $\mathrm{w} / \mathrm{c}=0.45$.

Table 1. The compositions of concrete mixes.

\begin{tabular}{|c|c|c|c|c|c|}
\hline \multirow{2}{*}{ Components } & \multicolumn{5}{|c|}{ Designation of concrete } \\
\hline & $\mathrm{P} 10 \mathrm{~K}$ & $\mathrm{P} 10 \mathrm{~K} 2$ & $\mathrm{P} 10 \mathrm{~K} 2 \mathrm{~S}$ & $\mathrm{P} 20 \mathrm{~K} 1$ & P20S \\
\hline CEM I $42.5 \mathrm{R}, \mathrm{kg} / \mathrm{m}^{3}$ & 383.3 & 383.3 & 383.3 & 383.3 & 383.3 \\
\hline Perlite $0-2 \mathrm{~mm}, \mathrm{~kg} / \mathrm{m}^{3}$ & 2.59 & 2.59 & 2.59 & 5.18 & 5.18 \\
\hline Sand $0-2 \mathrm{~mm}, \mathrm{~kg} / \mathrm{m}^{3}$ & 649.2 & 649.2 & 649.2 & 577.0 & 577.0 \\
\hline $\begin{array}{c}\text { Aggregate 2-16 mm, } \\
\mathrm{kg} / \mathrm{m}^{3}\end{array}$ & 1122.1 & 1122.1 & 1122.1 & 1122.1 & 1122.1 \\
\hline Water, $\mathrm{kg} / \mathrm{m}^{3}$ & 172.5 & 172.5 & 172.5 & 172.5 & 172.5 \\
\hline Superplasticizer, $\mathrm{kg} / \mathrm{m}^{3}$ & 3.833 & 3.790 & 3.975 & 5.211 & 5.829 \\
\hline $\begin{array}{c}\text { Copolymer of acetate, } \\
\mathrm{kg} / \mathrm{m}^{3}\end{array}$ & 3.833 & 7.666 & 7.666 & 3.833 & 0 \\
\hline Sarsil, $\mathrm{kg} / \mathrm{m}^{3}$ & 0 & 0 & 1.887 & 0 & 1.887 \\
\hline
\end{tabular}

\subsection{Methods}

Specific gravity was tested with pycnometric method after fragmentation of concrete samples in a ball mill to grain sizes smaller than $0.08 \mathrm{~mm}$. The air contained between the grains of powdered material was removed by inserting the pycnometer into the vacuum chamber and reducing the pressure to $2.33 \mathrm{kPa}$.

The apparent density was tested in accordance with PN-EN 1097-6 standard [19]. The total porosity was calculated based on the values of apparent density and specific density. [20].

Absorbency was tested according to PN-B-06250

Compressive strength tests for concrete were carried out in accordance with PN-EN 12390-3 standard [21], and tensile strength was tested according to PN-EN 12390-6 standard [22], in both cases after 28 days of maturation.

Frost resistance tests were carried out using the usual method in accordance with PN-B-06250 [21]. After 28 days of maturation in water, 6 samples were subjected to 100 freeze/thaw cycles, and 6 comparative samples were still in the water throughout the study period (age of samples - 112 days) [20].

During statistical analysis, for each investigated property of concrete the authors carried out:

- one-way ANOVA, where the factor is a combination of admixtures (with P10K1, P10K2, P10K2S, P20K1, P20S values)

- as a kind of confirmation ANOVA results (the fulfilment of ANOVA assumptions could be questioned because of small size of samples) nonparametric Kruskal-Wallis test is also calculated

- in the cases, where the factor is significant, also post- hoc Tukey HSD tests (see [23, 24]), were calculated to show all pairs of factor values, for which means are statistically different, we assume the significance level $\alpha=0.05$; this test is chosen as a compromise between sensitivity and the control of Type I error; It is also very well-known and widely used test

- for each investigated property, multi-way ANOVA (with type II tests) was calculated, as well to detect the strength of each of factors $\mathrm{P}, \mathrm{K}, \mathrm{S}$ (where factors $\mathrm{P}, \mathrm{K}$ and $\mathrm{S}$ are the quantity of perlite, copolymer of acetate and sarsil, respectively); also effect size for each of them was calculated with the help of $f$ Cohen coefficient (effect sizes allow us to estimate and classify impact of a factor, see [25]).

All statistical calculations and illustrations were made in R software (see [25]).

Scanning electron microscopy SEM (Quanta FEG 250 microscope by FEI, Hillsboro, USA) was employed to determine the morphology, microstructure of concrete.

\section{Results and discussion}

The test results, in the form of mean values and physical properties are given in Table 2, whereas the strength and frost resistance properties are presented in Table 3.

Table 2. Test results of physical properties.

\begin{tabular}{|c|c|c|c|c|}
\hline \multirow{2}{*}{$\begin{array}{c}\text { Determination } \\
\text { of concrete }\end{array}$} & $\begin{array}{c}\text { Specific } \\
\text { density }\end{array}$ & $\begin{array}{c}\text { Density } \\
\text { volume }\end{array}$ & $\begin{array}{c}\text { Total } \\
\text { porosity }\end{array}$ & $\begin{array}{c}\text { Water } \\
\text { absorption } \\
\text { by weight }\end{array}$ \\
\cline { 2 - 5 }$\left[\mathrm{g} / \mathrm{cm}^{3}\right]$ & {$\left[\mathrm{g} / \mathrm{cm}^{3}\right]$} & {$[\%]$} & {$[\%]$} \\
\hline P10K1 & 2.36 & 1.97 & 16.5 & 6.60 \\
\hline P10K2 & 2.33 & 1.95 & 16.3 & 6.75 \\
\hline P10K2S & 2.32 & 1.97 & 15.1 & 6.95 \\
\hline P20K1 & 2.19 & 1.78 & 18.7 & 7.33 \\
\hline P20S & 2.11 & 1.73 & 18.0 & 7.68 \\
\hline
\end{tabular}

Table 3. Test results of strength properties and frost resistance.

\begin{tabular}{|l|c|c|c|c|c|c|}
\hline & $\begin{array}{c}\text { Compre } \\
\text { ssive } \\
\text { strength } \\
\text { after 28 } \\
\text { days } \\
\text { nation of } \\
\text { concrete }\end{array}$ & $\begin{array}{c}\text { Tensile } \\
\text { strength } \\
\text { after 28 } \\
\text { days }\end{array}$ & $\begin{array}{c}\text { Loss of } \\
\text { weight }\end{array}$ & $\begin{array}{c}\text { Compre- } \\
\text { ssive } \\
\text { strength } \\
\text { after 100 } \\
\text { cycles - } \\
\text { pr. } \\
\text { witness }\end{array}$ & $\begin{array}{c}\text { Compre- } \\
\text { ssive } \\
\text { strength } \\
\text { after 100 } \\
\text { cycles }\end{array}$ & $\begin{array}{c}\text { Drop in } \\
\text { strength }\end{array}$ \\
\hline $\begin{array}{c}\mathrm{mm} \\
{[\mathrm{MPa}]}\end{array}$ & $\begin{array}{c}\# 100 \\
\mathrm{~mm} \\
{[\mathrm{MPa}]}\end{array}$ & {$[\%]$} & $\begin{array}{c}\# 100 \\
\mathrm{~mm} \\
{[\mathrm{MPa}]}\end{array}$ & $\begin{array}{c}\# 100 \\
\mathrm{~mm} \\
{[\mathrm{MPa}]}\end{array}$ & {$[\%]$} \\
\hline $\mathrm{P} 10 \mathrm{~K} 1$ & 33.4 & 4.03 & 1.4 & 38.1 & 36.5 & 4.2 \\
\hline $\mathrm{P} 10 \mathrm{~K} 2$ & 35.2 & 4.09 & 1.0 & 38.9 & 37.4 & 3.9 \\
\hline $\mathrm{P} 10 \mathrm{~K} 2$ & 34.2 & 4.06 & 2.0 & 37.9 & 36.2 & 4.5 \\
\hline $\mathrm{P} 20 \mathrm{~K} 1$ & 32.8 & 3.99 & 3.0 & 36.6 & 34.5 & 5.7 \\
\hline $\mathrm{P} 20 \mathrm{~S}$ & 29.5 & 3.97 & 4.5 & 34.4 & 31.5 & 8.4 \\
\hline
\end{tabular}

On the basis of the volumetric density test results, all concretes should be classified as lightweight concretes $\left(\rho_{\mathrm{V}} \leq 2000 \mathrm{~kg} \cdot \mathrm{m}^{-3}\right)$. In general, some dependencies can be observed while analysing the obtained average values of physical and strength properties. 
The increase in the addition of the porous perlite causes deterioration of both physical properties (increase in the total porosity and water absorption, deterioration of frost resistance) as well as durability (reduction of compressive and tensile strength). Different amount of the vinyl acetate copolymer admixture does not significantly change the tested concrete properties, while the hydrophobic admixture has a negative effect on most properties (increasing the absorbability of the weight, the frost resistance decreases, the compressive strength decreases).

\subsection{Feature "water absorption by weight"}

Performing a one-way analysis of variance was preceded by a check

- homogeneity of variance: the Brown-Forsythe test of homogeneity of variance gives p-value 0.129166, hence homogeneity of variance accepted.

- normality of model residues: p-value of the ShapiroWilk test normality of residues is 0.942992 , so we assume the normality of residues.

The one-way analysis of variance (the factor is the admixture system) gave the p-value of the $\mathrm{F}$ test equal to $3.66929 \mathrm{e}^{-13}$ and so the considered factor significantly differentiates the averages. Additionally, in Figure 1, apart from the confidence intervals for the mean value of the feature, the result of the Kruskal-Wallis nonparametric test also indicates the significance of differences in the distributions of individual groups, confirming the analysis of variance.

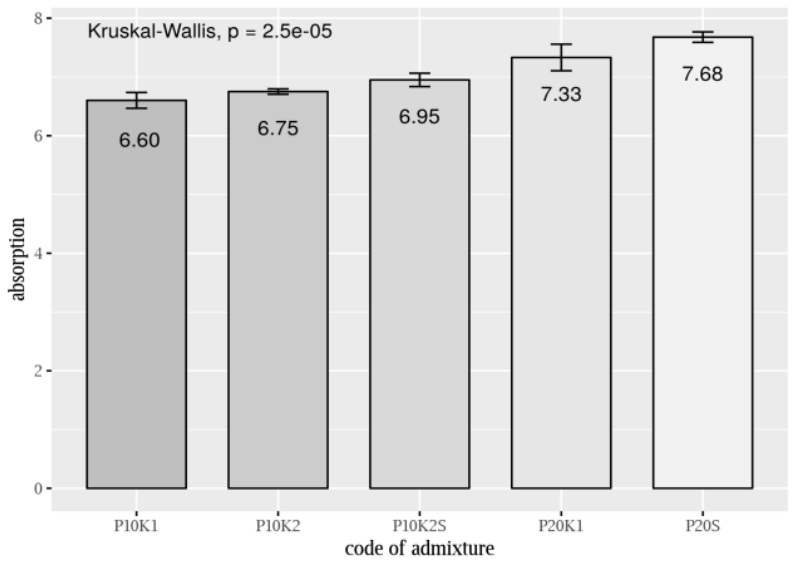

Fig. 1. Bar plots for "water absorption by weight" grouped by admixtures (with 95\% conf. intervals for means and KruskalWallis test).

The post-hoc Tukey HSD tests indicate 8 pairs where the mean differences are significant, for $\alpha=0.05$. The most significant difference is for the pair P20S-P10K1, the confidence interval for the difference in mean is $(0.86$, 1.30), while for pairs P10K2-P10K1, P10K2S-P10K2 the differences are not significant at the assumed level.

In addition, the significance of each factor (multivariate Anova, type II tests) was investigated. In the case of factor $\mathrm{K}$, the magnitude of the effect is negligible $(p$-value $=0.471), \mathrm{p}$-value $=0$ for factor $\mathrm{P}$ and $\mathrm{S}$, Cohen's factor $\mathrm{f}$ for $\mathrm{P}$ is 1.815 , while for $\mathrm{S}$ the ratio is 1.166 , so both are classified as large effects.

\subsection{Feature "compressive strength of samples curing in water (age of samples - 28 days)"}

Performing a one-way analysis of variance was preceded by a check of:

- uniformity of variance: the Brown-Forsythe test of homogeneity of variance gives p-value 0.0384611 , so homogeneity is slightly below the typical homogeneity acceptance threshold. This indicates caution while using the analysis of variance, in Figure 2 it can be seen that samples P10K1 and P10K2S are significantly more diverse than others,

- normality of the model's rest: p-value of the ShapiroWilk test normality of residues is 0.410861 , so $\mathrm{w}$ the normality of residues is assumed.

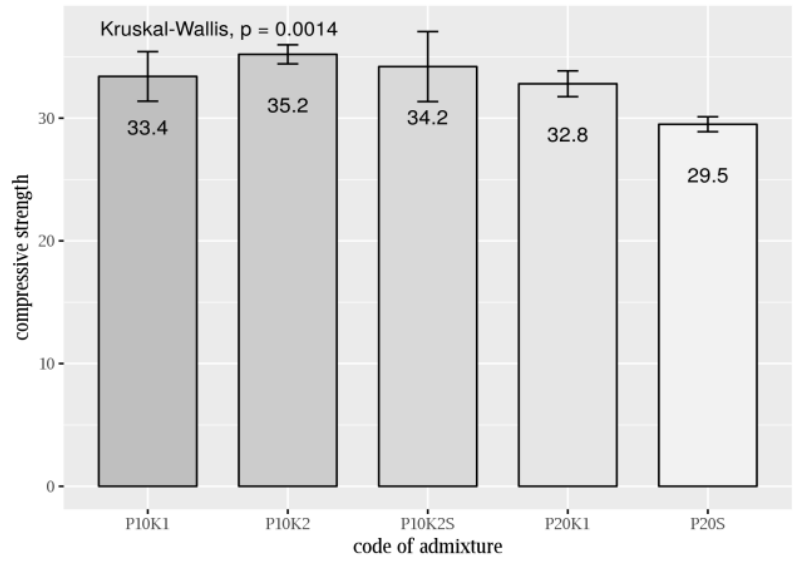

Fig. 2. Bar plots for "compressive strength of samples curing in water (age of samples - 28 days)" grouped by admixtures (with 95\% conf. intervals for means and Kruskal-Wallis test).

The one-way analysis of variance (the factor is the dopant system) gave the p-value of the $\mathrm{F}$ test equal to $3.13126 \mathrm{e}^{-05}$ and thus the considered factor significantly differentiates the averages, which is additionally confirmed by the nonparametric test result shown in Figure 2.

The post-hoc Tukey HSD tests indicate 4 pairs where the mean differences are significant, for $\alpha=0.05$. These are pairs P20K1-P20S, P10K1-P20S, P10K2S-P20S, $\mathrm{P} 10 \mathrm{~K} 2-\mathrm{P} 20 \mathrm{~S}$. The most significant difference is for the pair P10K2-P20S, the confidence interval for the difference in average is $(3.0,8.4)$. The other pairs, not mentioned above, have mean differences which are not statistically significant.

In addition, the significance of each factor (multivariate Anova, type II tests) was investigated. In the case of factor $\mathrm{P}$, the magnitude of the effect is irrelevant ( $p$-value $=0.517)$, for the factor $\mathrm{S} \mathrm{p}$-value is 0.06 is on the limit of significance, due to the small sample size to the effect of this factor should be approached with caution. Cohen's coefficient $f$ for this effect is 0.385 , so the medium effect. The factor $\mathrm{K}$ gives a significant impact, the $\mathrm{p}$-value is equal to 0 , Cohen's coefficient $\mathrm{f}$ is 0.645 , so it is a large effect.

\subsection{Feature "splitting tensile strength"}

Performing a one-way analysis of variance was preceded by a check of:

- homogeneity of variance: the Brown-Forsythe test 
of homogeneity of variance gives p-value 0.752349 , hence uniform variances,

- normality of model residues: p-value of the Shapiro-Wilk test normality of residues is 0.900848 , so we assume the normality of residues.

The one-way analysis of variance (the factor is the admixture system) gave the $p$-value of the $\mathrm{F}$ test equal to 0.225745 and thus the factor considered is not significant for the differentiation of averages, which is additionally confirmed by the nonparametric test result shown in Figure 3.

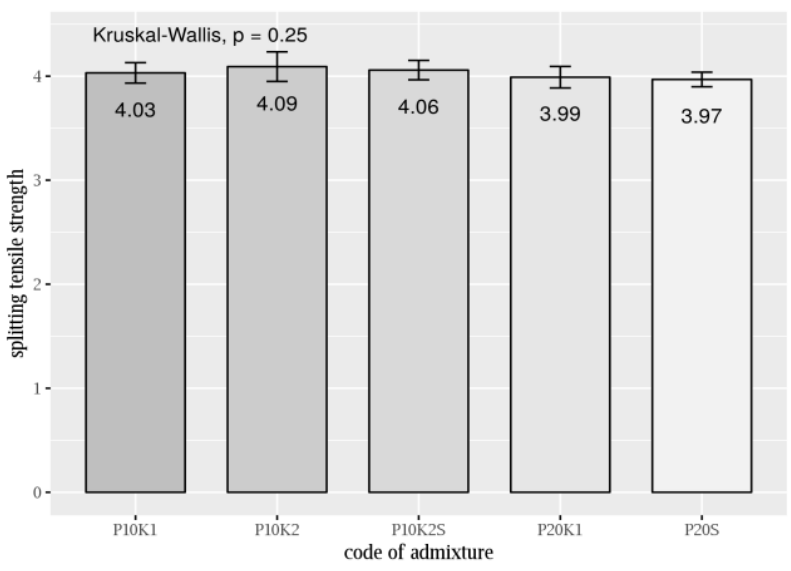

Fig. 3. Bar plots for "splitting tensile strength" grouped by admixtures (with 95\% conf. intervals for means and KruskalWallis test).

The data we have at our disposal is too weak to show differences due to the feature under consideration; similarly, testing the boundary effects did not bring any significant results.

\subsection{Feature "compressive strength after 100 freeze- thaw cycles (age of samples - 112 days)"}

Performing a one-way analysis of variance was preceded by a check of:

- homogeneity of variance: the Brown-Forsythe test of homogeneity of variance gives p-value 0.0328275 , so homogeneity is slightly below the typical homogeneity acceptance threshold, it indicates caution when using the analysis of variance. In Figure 4 it can be seen that samples P20K1 and P20S are significantly more diverse than others,

- normality of model residues: p-value of the ShapiroWilk test normality of residues is 0.252136 , so we assume the normality of residues.

The one-way analysis of variance (the factor is the admixture system) gave the $\mathrm{p}$-value of the $\mathrm{F}$ test equal to $3.42685 \mathrm{e}^{-09}$ and thus, the considered factor significantly differentiates the averages, which is additionally confirmed by the nonparametric test result shown in Figure 4.

The post-hoc Tukey HSD tests indicate 6 pairs for which the mean differences are significant, for $\alpha=0.05$. The most significant difference is for the pair P10K2$\mathrm{P} 20 \mathrm{~S}$, the confidence interval for the average difference is (4.1, 7.7), while for the pairs P10K2S-P20K1, P10K1P10K2S, P10K2-P10K2S, P10K2-P10K1 the average differences are not statistically significant.
In addition, the significance of each factor (multivariate Anova, type II tests) was investigated. Each of the factors is significant ( $p$-value $=0$ ) and Cohen's coefficients for $\mathrm{P}, \mathrm{K}, \mathrm{S}$, are $0.656,0.618,0.759$, respectively. Therefore, all effects are classified as large effect.

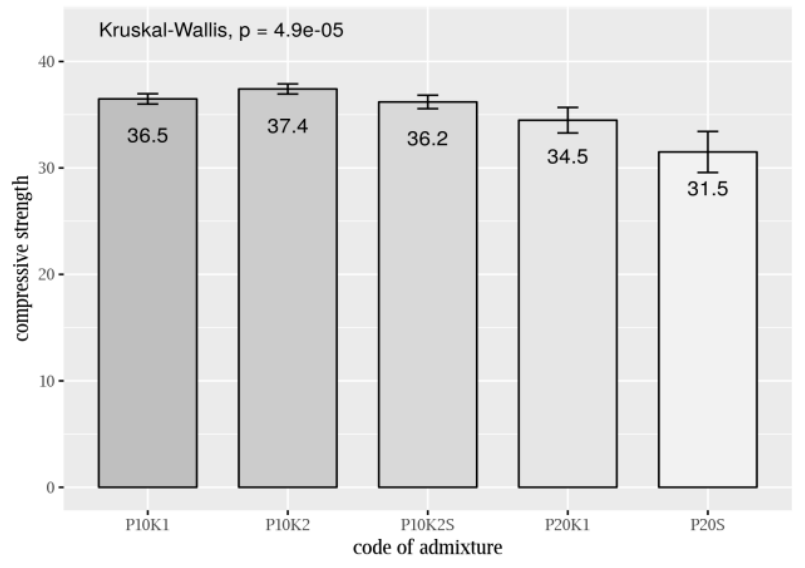

Fig. 4. Bar plots for "compressive strength after 100 freezethaw cycles (age of samples - 112 days)" grouped by admixtures (with 95\% conf. intervals for means and KruskalWallis test).

\subsection{Feature "compressive strength of samples curing in water (age of samples - 112 days)"}

Performing a one-way analysis of variance was preceded by a check of:

- homogeneity of variance: the Brown-Forsythe test of homogeneity of variance gives p-value 0.47654 , so the variance of the sample is homogeneous,

- normality of model residues: p-value of ShapiroWilk test normality of residues is 0.042316 , so it is on the border of acceptance; interpretation of the results of the analysis of variance requires confirmation with a nonparametric test.

The one-way analysis of variance (the factor is the admixture system) gave the p-value of the $\mathrm{F}$ test equal to $3.29832 \mathrm{e}^{-05}$ and thus, the considered factor significantly differentiates the averages, which is additionally confirmed by the nonparametric test result shown in Figure 5.

Post-hoc Tukey HSD tests indicate 5 pairs for which the mean differences are significant, for $\alpha=0.05$. These are the P20K1-P20S, P10K2S-P20S, P10K1-P20S, $\mathrm{P} 10 \mathrm{~K} 2-\mathrm{P} 20 \mathrm{~S}, \mathrm{P} 10 \mathrm{~K} 2-\mathrm{P} 20 \mathrm{~K} 1$ pairs. The most significant difference is for the pair P10K2-P20S, the confidence interval for the difference in mean is $(2.3,6.7)$, while for the remaining pairs the differences in the mean are statistically insignificant at the assumed level of significance.

In addition, the significance of each factor (multivariate Anova, type II tests) was investigated. Each of the factors is significant ( $\mathrm{p}$-value $=0$ ) and Cohen's coefficients for $\mathrm{P}, \mathrm{K}, \mathrm{S}$ are $0.385,0.387,0.454$, respectively. Thus, the first two are classified as medium effect and the last as a large effect.

\subsection{The "volumetric density" feature}

Performing a one-way analysis of variance was preceded 
by a check of:

- homogeneity of variance: the Brown-Forsythe test of homogeneity of variance gives p-value 0.206191 , so the variance of the sample is homogeneous,

- normality of model residues: p-value of the ShapiroWilk test normality of residues is 0.949065 , normality of residues takes place.

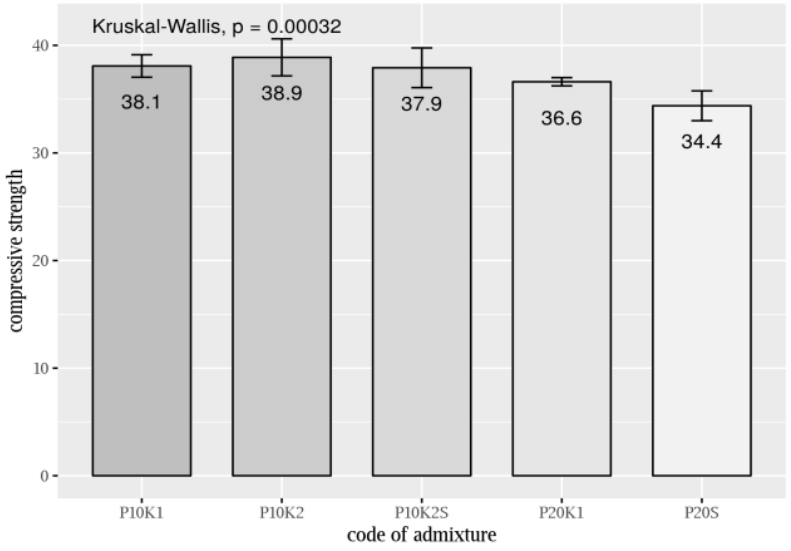

Fig. 5. Bar plots for "compressive strength of samples curing in water (age of samples - 112 days)" grouped by admixtures (with $95 \%$ conf. intervals for means and Kruskal-Wallis test).

The one-way analysis of variance (the factor is the admixture system) gave the $\mathrm{p}$-value of the $\mathrm{F}$ test equal to 0 , and thus the considered factor significantly differentiates the averages, which is additionally confirmed by the nonparametric test result shown in Figure 6.

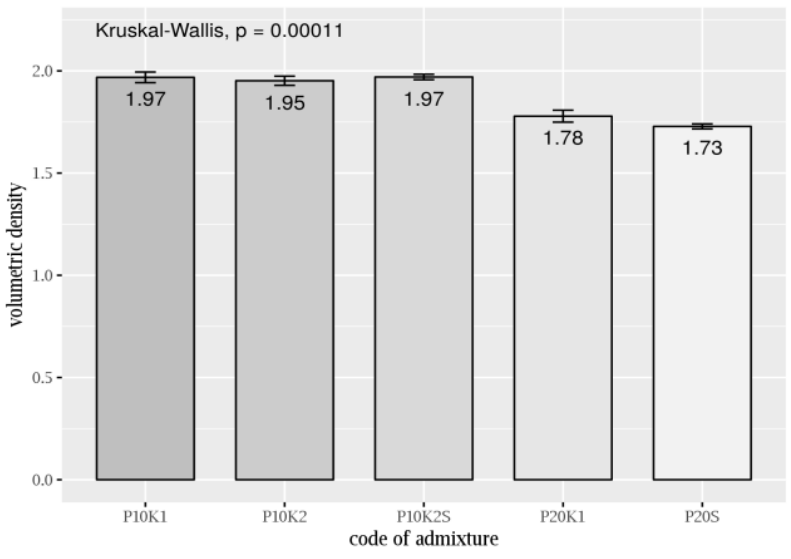

Fig. 6. Bar plots for "volumetric density" grouped by admixtures (with 95\% conf. intervals for means and KruskalWallis test).

The post-hoc Tukey HSD tests indicate 7 pairs for which the mean differences are significant, for $\alpha=0.05$. The most significant difference is for the pair P10K2S$\mathrm{P} 20 \mathrm{~S}$, the confidence interval for the average difference is (0.21, 0.28). For pairs P10K1-P10K2, P10K2S-P10K2, P10K2S-P10K1, the average differences are statistically insignificant at the assumed level of significance.

In addition, the significance of each factor (multivariate Anova, type II tests) was investigated. The only factor is $P(p$-value $=0)$, for the remaining ones, the $\mathrm{p}$-value is above 0.1. Cohen's coefficients $\mathrm{f}$ for perlite is 2.589 so it is a large effect.

\subsection{Microstructure of concrete}

The scanning electron microscope images (Fig. 7) showed the structure of selected concrete.

The interfacial transition zone, the ITZ between the perlite aggregate and the cement paste, as well as the Figure 7A (P10K1, 200x). Figure 7B depicts the structure of P20K1, which is rich in portlandite and ettringite. The C-S-H phase has become crystallised.
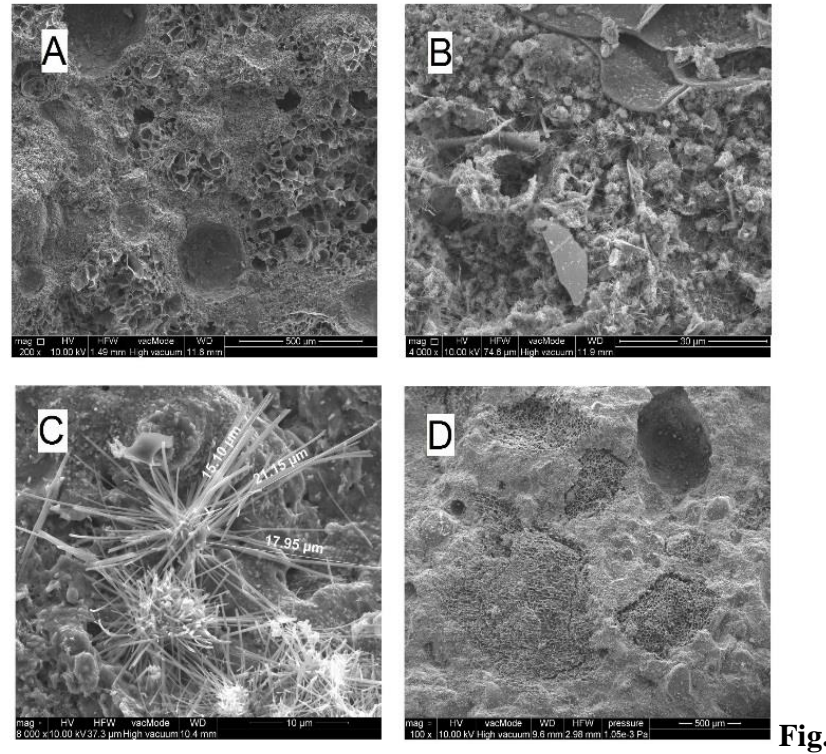

7. Micro-structure of lightweight concrete with perlite.

Perlite aggregate bonds well with concrete, no microcracks appeared between the aggregate and cement paste. The air pores are evenly distributed in concrete. In the P20S concrete structure, only ethylene vinyl acetate copolymer (Fig. 7C) is visible ettringite in the form of long needles, so-called hedgehogs; this structure is different than in another copolymer concrete. A weaker connection between the perlite aggregates and the cement paste in P20S was also observed (Fig. 7D). The lack of the copolymer and the hydrophobizing admixture caused a change in the concrete structure, which was reflected in the strength and frost resistance tests. According to L. Czarnecki, polymer molecules adsorb on the surface of the aggregate, causing chemical bonds to form between the components of the mix, causing changes in the microstructure and strength parameters [26]. The polymers should form a thin layer in the cement binder. Łukowski [27] states that the modification mechanisms of cement matrix caused by polymers are not fully discovered, especially in terms of their impact on the properties of concrete.

\section{Conclusion}

In view of the results presented above, the most important conclusions were drawn:

a) among statistically analysed traits in almost every case (apart from "splitting tensile strength", which may be caused by too small sample size), average values are significantly differentiated by the considered combinations;

b) in the case of weight absorption, the effect of adding the copolymer turned out to be insignificant; 
c) in the case of "compressive strength of samples curing in water" at 28 days the strongest effect was the factor $\mathrm{K}$, with 112 days effect size of all three factors was similar; d) The weakest interfacial transition zone (ITZ) observed through SEM analysis between the perlite aggregates and the cement paste contributed significantly to the worst physical and strength properties of this concrete.

\section{References}

1. D. Barnat-Hunek, P. Smarzewski, Composites Theory and Practice 15 (2) (2016)

2. D. Barnat-Hunek, M.K. Widomski, M. Szafraniec, G. Łagód, Materials 11 (2018)

3. A. Brás, M. Leal, P. Faria, Constr. Build. Mater 49 (2013)

4. D.K. Panesar, B. Shindman, Cem. Concr. Compos 34 (2012)

5. A. Moreira, J. António, A. Tadeu, Cem. Concr. Compos 49 (2014)

6. D. Barnat-Hunek, G. Lagód, R. Siddique, Constr. Build. Mater 155 (2017)

7. F. Aslani, G. Ma, D.L.Y. Wan, G. Muselin, J. Clean. Prod. 182 (2018)

8. M.C.S. Nepomuceno, L.A. Pereira-de-Oliveira, S.F. Sandrine, Constr. Build. Mater.166 (2018)

9. I.B. Topçu, T. Uygunoğlu, Constr. Build. Mater. 24 (7) (2010)

10. J. Petermann Moretti, S. Nunes, A. Sales, Constr. Build. Mater. 172 (2008)

11. S. Yang, X. Yue, X. Liu, Y. Tong, Constr. Build. Mater. 84 (2015)

12. D. Barnat-Hunek, J. Góra, W. Andrzejuk, G. Łagód,
Materials 11 (2018)

13. R. Siddique, Resour. Conserv. Recycl. 54 (2010)

14. I.G. Colombo, M. Colombo, M. Di Prisco, Cem. Concr. Res. 73 (2015)

15. W. Piasta, B. Zarzycki, Constr. Build. Mater. 140 (2017)

16. W. Piasta, J. Góra, T. Turkiewicz, Constr. Build. Mater.126 (2016)

17. Z. Suchorab, D. Barnat-Hunek, M.Franus, G.Łagód, Mater. 9 (2016)

18. D. Barnat-Hunek, R. Siddique, B. Klimek, M. Franus, Construction and Building Materials 142 (2017)

19. PN-EN 1097-6:2013-11 Tests for mechanical and physical properties of aggregates

20. PN-B-06250:1988 Ordinary Concrete [Polish Standard].

21. PN-EN 12390-3:2011 Testing hardened concrete Part 3: Compressive strength of test specimens

22. PN-EN 12390-6:2011 Testing hardened concrete Part 6. Tensile splitting strength of test specimens

23. K.S. Bordens, B.B. Abbott, Research Design and Methods. A Process Approach (McGraw-Hill, New York, 2008 )

24. D.J. Sheskin, Handbook of Parametric and Nonparametric Statistical Procedures (CRC Press 2011)

25. R. Core Team R: A Language and Environment for Statistical Computing. R Foundation for Statistical Computing, Vienna, Austria. https://www.Rproject.org/ (2018)

26. L. Czarnecki, Cem. Wapno Beton. 15 (2) (2010)

27. P. Łukowski, Arch Civ Mech Eng. 62 (2) 2016 